\title{
Hemophilia in Developing Countries: An Analysis of the First Data in Cameroon, Africa
}

\author{
CT Tagny ${ }^{1,2^{*}}, \mathbf{S}$ Moudourou $^{2}$, A Ndoumba $^{2}$ and D Mbanya ${ }^{1,2}$ \\ ${ }^{1}$ Faculty of Medicine and Biomedical Sciences, University of Yaoundé I, Yaoundé, Cameroon \\ ${ }^{2}$ University Teaching Hospital of Yaoundé, Cameroon
}

"Corresponding author: Claude Tayou Tagny, Faculty of Medicine and Biomedical Sciences, University of Yaoundé I, BP: 4806 Yaoundé Cameroon, Tel: 002379306 00 83; Fax: 00237222117 38; E-mail: tayouclaude@yahoo.fr

Rec date: Mar 12, 2014, Acc date: Apr 29, 2014, Pub date: May 01, 2014

Copyright: () 2014 Tagny CT, et al. T This is an open-access article distributed under the terms of the Creative Commons Attribution License, which permits unrestricted use, distribution, and reproduction in any medium, provided the original author and source are credited.

\begin{abstract}
Background and Objective: In sub-Saharan Africa, hemophilia remains a huge problem mainly because of ignorance of the disease, limited screening capabilities and access to treatment. This review aims to discuss the characteristics of Cameroonian patients living with hemophilia.

Methods: A retrospective study was done on the data of four main reported studies between 1972 and 2010 in Cameroon. Epidemiological, clinical and biological features of PLWH in Cameroon were analyzed.

Results: The mean age of the patients was between 14 and 16.2 years. All hemophiliacs reported by the studies were male. For most patients, the frequency of bleeding episodes ranged from 2-15 bleeds per year. Chronic joint complications were found in almost all patients in the 2010 study. Hemophilia A was more common than B, representing $88.4 \%$ and $87.5 \%$ in the 2008 and 2010 studies respectively. All the 37 patients reported in the 2010 study were tested negative for HIV in spite of multiple transfusion histories.

Conclusion: Some features of hemophilia in Cameroon are different from those of other African countries. However, as in many countries, the biggest long term challenge is the constant availability of clotting factors concentrates for patients.
\end{abstract}

Keywords: Hemophilia; Developing countries; Cameroon; Characteristics

\section{Introduction}

The difficulties of managing congenital bleeding disorders are mostly due to their familial nature, high morbidity, significant physiological and psychosocial complications [1]. In sub-Saharan Africa, the problem remains huge mainly because of ignorance of the disease, limited screening capabilities and poor access to treatment $[2,3]$. In these resource-limited areas, a strategic plan for managing hemophilia should start with the mastery of local characteristics of the disease in order to optimize the effectiveness of treatment availability. Some studies on these characteristics frequently reported a predominance of severe cases, a relatively high frequency of joint complications, a high prevalence of transfusion-transmissible infections and a life expectancy three times shorter [4-9]. More genetic differences between African and Caucasian hemophiliacs include the frequency of mutations and haplotypes of coagulation factors, and their relationship with the development of inhibitors $[10,11]$.

In Cameroon, the 2014 number of persons living with hemophilia (PLWH) is estimated at about 1800 , but only about a hundred are registered. This review aims to discuss the characteristics of Cameroonian PLWH reported by the first studies available. Four main studies reported data on hemophilia between 1972 and 2010 at the Faculty of Medicine and Biomedical Sciences, University of Yaoundé I. No other data is available even at a National level. They were studies of
Chendjou in 1972 [12], Edzoa in 2002 [13], Nda in 2008 [14] and Tiga in 2010 [15]. These works intended to describe the epidemiological, clinical and biological features of PLWH in Cameroon. A description of the comprehensive care of hemophilia in Cameroon is detailed below.

\section{Epidemiological data of hemophilia in Cameroon}

The mean age of the patients was between 14 and 16.2 years (Table I). Previous studies conducted in Côte d'Ivoire, Senegal and South Africa reported $t$ similar young ages of patients $[4,5,16]$. The first abnormal bleeding was reported during circumcision in the months following birth for more than half of the cases. However, the mean age of patients at time of diagnosis was greater than the one at onset of abnormal bleeding; suggesting that patients did not immediately go to a hospital having the technical capabilities for a correct diagnosis.

All hemophiliacs reported by the studies were male. Given its recessive sex-linked transmissibility, hemophilia is rarely found among African women $[4,5,16]$. However, women carrying the abnormal gene may have a mild to moderate deficiency of factor VIII or IX and may suffer from bleeding disorders notably gynecological or obstetric $[17,18]$. A woman was suspected to have hemophilia in the study of Nda. Unfortunately, further investigation could not be made in this patient to exclude this hypothesis.

In all four studies, hemophiliacs were recruited mainly in urban areas. All of them came spontaneously at the hospital for bleeding 
Citation: Tagny CT, Moudourou S, Ndoumba A, Mbanya D (2014) Hemophilia in Developing Countries: An Analysis of the First Data in Cameroon, Africa. J Blood Lymph 4: 119. doi:10.4172/2165-7831.1000119

Page 2 of 4

disorders. In fact, the low research budgets did not allow community investigation, so as to screen, diagnose and recruit patients at their locality

The level of education of hemophiliacs reported by Tiga [15] revealed that $87.5 \%$ of them had a primary or secondary school level. It does not seem to be different from that of the children of the same age group in the general population and not registered as PLWH in Cameroon.

\begin{tabular}{|c|c|c|c|c|c|}
\hline \multicolumn{2}{|c|}{ Epidemiological characteristics } & \multicolumn{4}{|c|}{ Studies and number of cases } \\
\hline & & Chendjou D & Edzoa EF & Nda M & Tiga $\mathrm{F}$ \\
\hline & & -1972 & -2001 & -2008 & -2010 \\
\hline & & $n=9$ & $\mathrm{n}=28$ & $n=26$ & $\mathrm{n}=40$ \\
\hline \multicolumn{2}{|l|}{ Mean age (years) } & 16 & 15,4 & 14 & 16,2 \\
\hline \multirow{5}{*}{ Age group (n) } & $0-4$ years & 2 & 6 & 4 & 5 \\
\hline & $5-9$ years & 3 & 11 & 6 & 10 \\
\hline & $10-14$ years & 3 & 5 & 6 & 6 \\
\hline & $15-19$ years & 1 & 4 & 4 & 6 \\
\hline & $\geq 20$ years & 0 & 2 & 6 & 13 \\
\hline \multirow{2}{*}{ Gender (n) } & Male & 9 & 28 & 26 & 40 \\
\hline & Female & 0 & 0 & 0 & 0 \\
\hline \multirow{2}{*}{ Origin (n) } & Urban & 9 & 22 & 21 & 33 \\
\hline & Rural & 0 & 6 & 5 & 7 \\
\hline \multirow{4}{*}{ Education level (n) } & None & I & I & I & 3 \\
\hline & Primary & l & l & I & 15 \\
\hline & Secondary & I & I & I & 17 \\
\hline & University & I & I & 1 & 5 \\
\hline \multirow{2}{*}{ Type of hemophilia (n) } & A & 8 & 20 & 23 & 35 \\
\hline & B & 1 & 8 & 3 & 15 \\
\hline \multirow{3}{*}{ Severity $(n)$} & Mild & 0 & 1 & 0 & 1 \\
\hline & Moderate & 0 & 7 & 9 & 14 \\
\hline & Severe & 9 & 20 & 17 & 25 \\
\hline
\end{tabular}

Table 1: Demographic characteristics of hemophilia in Cameroon

\section{Clinical features of hemophilia in Cameroon}

Medical history of Cameroonian hemophiliacs reveals frequent transfusions of red cell concentrate or whole blood mostly to deal with severe anemia, and fresh frozen plasma (FFP) to correct severe deficiency in clotting factor. Indeed, among the 40 patients enrolled in the 2010 study, 36 were transfused at least 1 time, after a bleeding episode. For most patients, the frequency of bleeding episodes ranged from 2-15 per year, a range often found in Europe [19]. In case of prolonged bleeding, and in the absence of clotting factor concentrates, blood transfusion remains the only solution, especially when acute bleeding occurs in anemic patients.

History of hemophilia in the family was frequent (up to $70 \%$ of cases) as in Senegal [5]. Nevertheless, it is not yet clear whether the transmissibility of the disease is higher in Africa and whether the proportion of 1 hemophiliac /10000 individuals described is strictly applicable [20]. Cameroonian population is estimated to $18-20$ million persons. Thus, population of hemophiliacs may represent 1800 to 2000 persons. The frequency of spontaneous mutations is not mastered in the context.

Extensive work has been done on the main clinical signs of hemophilia in Cameroon. It is currently being analyzed. However, male circumcision was the main circumstances of diagnosis, followed by mucosal bleeding. Hemarthrosis and chronic joint complications were found in almost all patients in the 2010 study. Amblee revealed a high frequency of hemarthrosis already described in other African countries $[4,5]$ and therefore a real need for preventive therapy. 


\section{Laboratory findings}

The type of hemophilia was reported in the two most recent studies. A semiautomatic machine (Option 4 Plus, BioMerieux, France) was used for a chronometric measurement of levels of factor VIII and IX based on activated prothrombin time (APTT). Hemophilia A was more common than B, representing $88.4 \%$ and $87.5 \%$ in the 2008 and 2010 studies respectively. This predominance of type A hemophilia has been reported in previous African studies [21,22]. However, the distribution of hemophiliacs according to the severity of the disease is not the same, the severe type seeming to predominate in Cameroon and South Africa [4] but not in West Africa [5].

Screening markers of transfusion transmissible infections are of paramount importance in Cameroon given the frequent blood transfusions of PLWH. Only the results of the 2010 study were available. Screening for HIV infection was based on both rapid immuno-chromatographic assay and EIA Ab/AgP24 assay. The screening for $\mathrm{HBV}$ and $\mathrm{HCV}$ infection used rapid immunochromatographic assay and EIA anti-HCV assay respectively. That of syphilis used combination of a non-treponemal test (RPR or VDRL) and a treponemal test (TPHA). All the 37 patients reported in the study of Tiga were tested negative for HIV in spite of a history of multiple blood transfusions. Some explanations may be the young age of the patients not associated with risky sexual behaviors and a systematic screening for HIV infection on all blood donations prior to transfusion since 1987. Moreover, the screening used EIA Ab/AgP24 test reported most efficient EIA assays in Yaoundé [23]. However, only 6 persons were more than 15 years old in the study conducted in 2010 and were liable to have risky sexual behavior. Thus a precise prevalence of HIV could not be determined in such small study sample. Hepatitis $\mathrm{C}$ infection was the most frequent transfusiontransmissible infections in 2010 ( 5 positives cases versus 1 positive case for Hepatitis B). This is the most common infection reported in PLWH in Africa [7,24]. Indeed, this virus is primarily transmitted by blood transfusion. Unfortunately, screening for hepatitis $\mathrm{C}$ infection is not as safe as HIV infections. The silent serological period is longer, the use of single rapid tests is common, and these rapid test are less sensitive compared to the EIA test used for HIV screening. In addition, the systematic screening of HCV infection in blood donation was introduced between 2001 and 2005, after that of HIV (1987), HBV (60's) and syphilis (60's).

The absence of HBV infection is still poorly understood because this observation in contrasts with that of other African studies [5,7]. One would expect a high prevalence of infection in boys exposed to their school environment. Studies on larger group of patients and the use of more sensitive tests are needed to confirm that hypothesis. Meanwhile, the recommendation of vaccination against Hepatitis B infection in hemophilia should be the rule whenever possible.

\section{The management of hemophilia in Cameroon}

The Ministry of Health in Cameroon has not yet implemented a specific program for a comprehensive care of hemophilia, although a draft of a strategic plan was developed. The management of PLWH is currently integrated into a global control of congenital diseases, whose activities are insufficient for rapid improvement of hemophiliac care. However, since 2008 a partnership between the World Federation of Hemophilia, the Hemostasis Unit of "Hopitaux Universitaires de Genève" and the University Teaching Hospital of Yaoundé (UTHY) created an hemophilia treatment center (HTC) located in the
Hematology Unit of UTHY. The center provided free screening and diagnosis of the disease, medical care and free medication when available. In addition, since 2006, Cameroonian PLWH have an association were they can be educated, informed and socially integrated. Cameroonian Association of Hemophilia (CAH) was officially created in 2006 and was affiliated to hemophilia associations of the World Federation of Hemophilia (WFH) in 2008 during the 19th congress of the federation in Turkey. Hemophiliacs meet once a month to discuss the difficulties of their care and their social activities, share their difficulties and ideas for improvement of the status of the association, including in sensitization, technical and financial assistance. However, this association is not well known. Thanks to their partners, an extended screening project, information and education on hemophilia started few years ago. It will map the distribution of the disease and organize a comprehensive care around a single center. Improvement has been noticed these last years: a register has been created and the number of patient registered is increasing, patients are visiting the center more frequently and are medical care is more regularly provided. Further research studies on hemophilia care have been conducted and their results in press. Unfortunately genetic counseling on this hereditary condition has not been set up due to absence of local equipment for genetic diagnosis and lack of financial means for analysis in foreign laboratories.

Reinforcement of the diagnosis and management of hemophilia and its complications has started in Cameroon, but for the other congenital bleeding disorders, their diagnosis and management are still in an embryonic stage.

The screening for von Willebrand factor (vWF: Ag) and ristocetin cofactor his (vWF: Rco), the platelet aggregation tests and screening for antiphospholipid antibodies are not yet feasible, as well as the extraction of DNA for genomic analysis, though, Von Willebrand disease is 100 times more common than hemophilia $[25,26]$.

The biggest long term challenge is the regular availability of clotting factors concentrates for patients. Currently, drug therapy is often based on transfusion of blood components, use of anti-fibrinolytic medication and occasionally clotting factor concentrates provided irregularly by partners. Indeed, the latest drugs are too expensive for developing countries, costing 0.7 to 1 euro per unit [27]. The use of cryoprecipitate would cost 100 times less and would be accessible to blood banks in developing countries $[27,28]$. However, it requires a regular and adequate supply of blood products, a good system of medical selection of blood donors and a good quality of screening blood donation. The involvement of public authorities and the constant support of partners are essential for an efficient and sustainable care.

\section{References}

1. Franchini M, Lippi G (2009) Recent improvements in the clinical treatment of coagulation factor inhibitors. Semin Thromb Hemost 35: 806-813.

2. Srivastava A, Chuansumrit A, Chandy M, Duraiswamy G, Karagus C (1998) Management of haemophilia in the developing world. Haemophilia 4: 474-480.

3. World Federation of Hemophilia (2006) Treatment for all. A vision for improvement. Montréal.

4. Hazewinkel MH, Hoogerwerf JJ, Hesseling PB, Hartley P, MacLean PE, et al. (2003) Haemophilia patients aged 0-18 years in the Western Cape. S Afr Med J 93: 793-796. 
Citation: Tagny CT, Moudourou S, Ndoumba A, Mbanya D (2014) Hemophilia in Developing Countries: An Analysis of the First Data in Cameroon, Africa. J Blood Lymph 4: 119. doi:10.4172/2165-7831.1000119

Page 4 of 4

5. Diop S, Thiam D, Toure Fall AO, Diakhate L (2003) [Epidemiologic aspects and medical-social impact of hemophilia at the University Hospital Center in Dakar]. Med Trop (Mars) 63: 139-142.

6. Ghosh K (2004) Management of haemophilia and its complications in developing countries. Clin Lab Haematol 26: 243-251.

7. Langar H, Triki H, Gouider E, Bahri O, Djebbi A, et al. (2005) [Bloodtransmitted viral infections among haemophiliacs in Tunisia]. Transfus Clin Biol 12: 301-305.

8. Thejpal R, Bassa F, Nkosi D (2006) Causes of Death in Haemophiliac patients at a treatment center in KwaZulu Natal, South Africa. Haemophilia 12: 72-74.

9. Fakunle EE, Shokunbi WA, Shittu OB (2007) Incidence of factor FVIIIC deficiency in live male infants undergoing circumcision in South West, Nigeria. Haemophilia 13: 567-569.

10. Li X, Drost JB, Roberts S, Kasper C, Sommer SS (2000) Factor IX mutations in South Africans and African Americans are compatible with primarily endogenous influences upon recent germline mutations. Hum Mutat 16: 371.

11. Viel KR, Ameri A, Abshire TC, Iyer RV, Watts RG, et al. (2009) Inhibitors of factor VIII in black patients with hemophilia. N Engl J Med 360: 1618-1627.

12. Chendjou D (1972) Caractéristiques cliniques de l'hémophilie à Yaoundé. Thèse de doctorat en médecine, Université de Yaoundé I.

13. Edjoa EF (2002) Profil clinique de l'hémophile Camerounais ; Thèse de doctorat en médecine, Université de Yaoundé I.

14. Nda M (2006) Profil hémostatique des hémophiles suivis au CHU de Yaoundé. Thèse de doctorat en médecine, Université de Yaoundé I.

15. Tiga F (2010) Serological findings among Cameroonian hemophiliacs. Thèse de doctorat en médecine, Université de Yaoundé I.

16. Tolo A, Gnui KE, Kouakou B, Sanogo I, Sangare A (2005) Profils clinique, hématologique et évolutif de l'hémophile du noir africain expérience du service d'hématologie clinique du CHU de Yopougon (Cote-d' ivoire). Médecine d'Afrique Noire 5212: 653-656.
17. Plug I, Mauser-Bunschoten EP, Bröcker-Vriends AH, van Amstel HK, van der Bom JG, et al. (2006) Bleeding in carriers of hemophilia. Blood 108: 52-56.

18. James AH (2010) Women and bleeding disorders. Haemophilia 16 160-167.

19. Krebs H, Spannagl M, Schramm W; für die teilnehmenden Behandlungseinrichtungen (2009) [Morbidity and mortality of patients with haemophilia in Germany 2007/2008]. Hamostaseologie 29: S7-12.

20. Nathwani AC, Tuddenham EG (1992) Epidemiology of coagulation disorders. Baillieres Clin Haematol 5: 383-439.

21. Abdulle OA, Mohamud MS, Isse MM, Chistolini A, Papacchini M, et al. (1989) Haemophilia in Somalia. Haemostasis 19: 100-104.

22. Mba EC, Kulkarni AG, Fleming AF, Emembolu J (1995) Haemophilia in northern Nigeria. Cent Afr J Med 41: 59-62.

23. Tagny CT, Mbanya D, Leballais L, Murphy E, Lefrère JJ, et al. (2011) Reduction of the risk of transfusion-transmitted human immunodeficiency virus (HIV) infection by using an HIV antigen/ antibody combination assay in blood donation screening in Cameroon. Transfusion 51: 184-190.

24. Adewuyi JO, Coutts AM, Levy L, Lloyd SE (1996) Haemophilia care in Zimbabwe. Cent Afr J Med 42: 153-156.

25. Bowman M, Hopman WM, Rapson D, Lillicrap D, James P (2010) The prevalence of symptomatic von Willebrand disease in primary care practice. J Thromb Haemost 8: 213-216.

26. Srivastava A (2005) von Willebrand disease in the developing world. Semin Hematol 42: 36-41.

27. El-Ekiaby M, Sayed MA, Caron C, Burnouf S, El-Sharkawy N, et al (2010) Solvent-detergent filtered (S/D-F) fresh frozen plasma ad cryoprecipitate minipools prepared in a newly designed integral disposable processing bag system. Transfus Med 20: 48-61.

28. Burnouf T, Goubran HA, Radosevich M, El-Ekiaby M (2007) Preparation and viral inactivation of cryoprecipitate in blood banks in resourcelimited countries. ISBT series 2: 121-128. 